\title{
Some Considerations on Funeral Rites in ONDO Kingdom, a File Server and a Novel Customized Control
}

\author{
Adenugba, D. A. \\ Department of Physics \\ The Federal University of Technology, Akure \\ P.M.B 704, Akure, Ondo State. Nigeria.
}

\begin{abstract}
Funeral is universal and continuous. Using oral interviews, genuine facts were unravelled about funeral customs of peaceloving Ondo people from old folks who had been involved in several funerals for many years. It was discovered that Ondos have special occasional food and attires. Certain garments and items like Akoun reveal celebrants; in-laws are assigned duties and materials to bring to funeral. Deceased children and relatives submit worthy items such as goats. Baba Musoku, monitors and coordinates the funeral activities. Corpse washing and grave digging are uniquely performed. Wives kneeing before a celebrant traditionally has implications, but not that of punishment. A server was developed for file manipulations and the exposed functionalities work accurately. A picture box was customized for image display; the functionalities are adequate and flexible to handle some image operations. Through a client application, AtereSoft, the functionalities in the customized component and server are exposed and found to work to specifications. Besides, selected items with straight-to-the-point-comments are shown in AtereSoft, cleverly putting traditions in the computer. Children born in foreign land to Ondo folks will benefit tremendously from this work and parent(s) will be reminded of home. Software developers will find the server and component developed with Microsoft Visual Studio, 2013 invaluable in their works. Areas of further attention are addressed.
\end{abstract}

\section{General Terms}

Agbada, Customized control, File server, Unakere

\section{Keywords}

Aso Oke, Class library, Dock, Funeral, Baba Musoku, Ondo

\section{INTRODUCTION}

Funeral is as old as man on earth. Folks died, funeral followed all over the world. Funeral is part of nature and it is universal. An object repeatedly use may create false impression that one understands everything about that particular object. This is also true of funeral traditional beliefs in all societies. Several young people attended funerals, but with little understanding of what transpired behind the closed doors. Doors of many meetings; doors of items to bring to the funeral and why. Also, doors of who Baba Musoku (Father of burial) is and his activities; doors of certain attires and items that are used at funeral. Indeed, several doors are to be unlocked for both indigenes and non-indigenes to lucidly perceive funeral rites in Ondo town. Besides funeral custom of the Ondos, the second section of this paper deals with the development of customized control using existing picture controls on UserControl, as well as the development of a file server.
There are intrinsic controls that come with Microsoft Visual Studio, 2013. All these controls have unique names and properties which distinguish them from one another. The opportunity granted to Software Developers to customize controls for specific purpose further extends the functionalities of the controls and empowers them to perform incredible feats swiftly. Without controls, intrinsic and/or customized, there are no software applications. Thus, controls are the indisputable building blocks for client and server applications[1-7]. The objectives of this paper are to develop a customized control for picture box control, using the most popular high-level computer programming language, Microsoft Visual Studio, 2013. Also, we discuss some rich funeral customs of Ondo kingdom in Ondo State in Nigeria, West-Africa. Specifically, we discuss Baba Musoku, grave digging, burial clothes and ceremonial food preferred mostly by the loving and generous folks of Ondo town. Indeed, picture box control will be customized for image display; provision of utilities such as save, copy and print of images will assist images to be persisted to the joy of users. Also, a new class library was developed for file manipulations. A client application, AtereSoft, will be developed to test the accuracy and flexibility of the server and the picture box customized control. Moreover, through AtereSoft traditions will be put inside the computer as selected items of Abebe (hand fan), Unakere, Akoun and Ewe (leaf) will be displayed and animated. In doing this, teaching of some items to nonindigenes, both adults and young ones, about Ondo unique cultural items takes place. Since the product of teaching is learning, we joyfully permit users to learn Ondo cultures.

\section{DATA COLLECTION}

Generally, no one wants to talk about death. It appears chatting about it will hasten its coming. To get people to talk about various aspects of funeral is very difficult when a young person died. For one, sad folks are not favourably disposed to talk. Being literally eaten up by anguish, people will shun conversing with anyone who wishes to know about funeral in their cultural settings. However, when a very old person joined his/her fathers, people will chat and chat well and gladly.

I was deeply involved in a burial and burial ceremony (BBC) recently when my father died at 107 years, which afforded me the uncommon privilege to interact with family members seen recently and long seen, as well as natives with broad, deep and rare knowledge of the cultures and customs of Ondo people. At least over hundred but less than two hundred people were orally discussed with. The atmosphere was a joyful one; paper work won't work here as most of them are uneducated. 


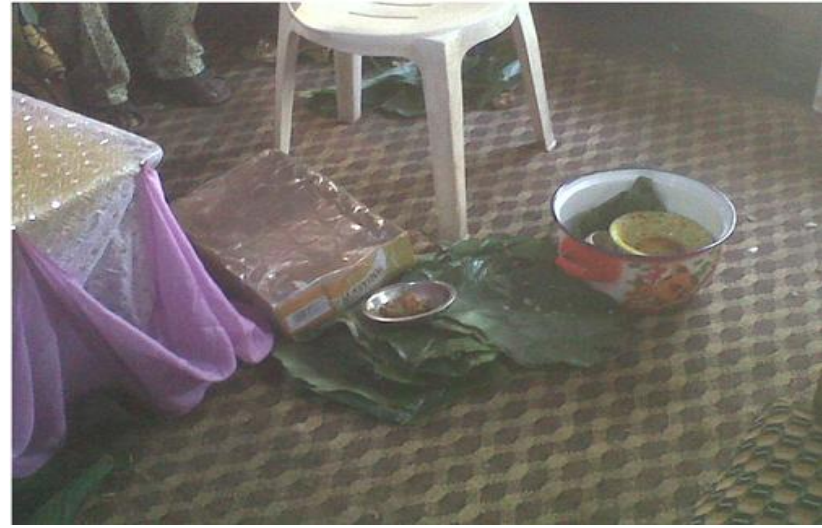

Figure 1: Leaf wrappers of Pounded Yams on the floor. Pan for soup; plates for serving. Empty mineral crate

More so, no one carries paper, yes, questionnaire, where plates of food and leaf- wrappers of pounded yams (PYs) and drinks were seen as shown in figure 1, and odour of sweet soups perfumed the air. But my mobile phone assisted to record voice unnoticed, which was later employed for this research. The interviewees were all willing to chat with me, uninhibited by any gadget hidden in my pocket. They were willing to chat because they see it as a chance to educate me about Ondo culture concerning funeral. Old people in Ondo are always willing to educate younger people. One of them at this occasion, a socialite, though a female, divulged many facts. The age of these people, relatives and non-relatives, is between 65-82 years.

Although they are old, many of them still have their teeth intact and health untouched by illness, yet gray hair and body wrinkles are good betrayer of old people. The interview location varies from inside the sitting room, verandah, under the canopies to the kitchen where the wives were cooking in Ondo town to inside the car while travelling back to Akure, the state capital of Ondo State in Nigeria. The interviewees claimed to have being involved in funeral for a period of time ranging from 15-40 years; "When the in-laws", an old male elder with kola-stained teeth said, "pulled off their clothes to serve the elders."

Several pictures taken recently, some of which are used in this paper, were procured through Sonny Video Camera, a blackberry and Nokia handset. With open camera, people were not very willing to talk that explains why the pocket gadgets did most of the jobs. After editing the pictures taken, two hundred images were obtained, which could be loaded seamlessly with the novel customized picture box control. Besides, by the design here, any picture in dvPicts folder will also be shown. One hundred pictures taken many years back were added.

\section{IMPLICATIONS OF WIVES ON THEIR KNEES}

The money given to the wives in the kitchen is the usual traditional way of doing things in Ondo. It is not to bribe them to answer my questions. When wives (your brothers' wives and relatives' wives) sight a celebrant, they knee down in front of the celebrant, praising him or her; and raising up their closed fists carefully placed on their forehead, they will say, Olowo O ri mi (The one who paid my dowry). Without any option, the celebrant will bring out good Naira to give to them. While celebrants are spending money, wives are making money and cooking for members of that household. What now has been shifted in most occasions to Olowosibi (cookers, food contractor, mostly women contracted out food to, to prepare for occasions such as naming, house-warming and funeral ceremonies) was previously the task of the wives. So wives cook for occasions also, but not much nowadays. This wives' traditional way of getting money from the celebrants is not a function of age; old and young wives, do it. Thus, all celebrants should have change of various Naira denominations with them to spend, for not only the wives, but for the drummers as well.

Besides being a spender, a celebrant is known by the Uankere (a small short turf of cow hair) he/she holds, as well as Akoun (beads, mainly deep red in colour) he/she wears. Anyone can directly weep at a funeral or induce to weep, but it is not everybody who wears Akoun and holds Uankere. These items mark out chiefs and His Royal Highness also in Ondo town. Although the Rulers use them always; it is occasional items for non-rulers. Pictures of these items could be seen, copied and printed through the client application developed for this work.

\section{SOME FUNERAL RITES IN ONDO KINGDOM}

There are some terms quite peculiar to burial and burial ceremony (BBC) in Ondo town, which will be found in the list of abbreviations and as you read along. Some could not be cast completely in English Language, but at least nonindigenes could still follow the discussion with understanding.

\subsection{Baba Musoku}

When a deceased is to be buried in Ondo town, Baba Musoku is appointed from among the family of the deceased. Baba Musoku (Ondo dialect for, roughly put, Father of burial in English Language). We also have Iya Musoku (Mother of burial). Second Baba Musoku is also appointed. The duo controls all the activities, as well as the complaints throughout the BBC. The various meetings are chaired by Baba Musoku; in his absence, the second Baba Musoku takes over. The appointment criteria for Baba Musoku are based on nearness to the deceased, as well as age. A younger person who is the nearest kinsman and kinswoman to the dead is appointed to be Baba Musoku and Iya Musoku respectively. Appointment of Iya Musoku is not very popular and activities could proceed without her. However, without Baba Musoku nothing could be done. Therefore, his appointment is done during the first meeting.

\subsection{Digging of Grave}

Digging of grave in Ondo is not different from other places around the world. The traditional six feet depth is used, but the grave yard of Baba Olomo (Father of children or anyone who gives birth) should not be completed in a single day. When a professional grave digger was asked why and what will happen if completed in a day, his response was that, "That is what we are used to in this town". No one could proffer any reasonable reason why it has to be so. In this neat town, it is the task of the in-laws to dig the grave of their father-in-law/mother in-law as seen in figure 2 at the verandah of Pa Ateremonuwon Adenugba recently in Ondo town. The digging was completed the following day at about 9.45am being Baba Olomo. 


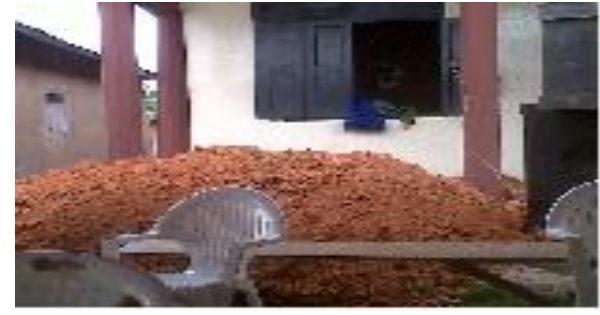

Figure 2: Grave Digging at Oshinrungboye Lane, Ondo

\subsection{The Prided Food of Ondo People}

Ondo people (OP) value quality food greatly. During occasions the indispensable food of OP is pounded yam that must not have ema (Ondo dialect for small-small-yam-pebble inside pounded yam). Any pounded yam (PY) with ema brought to an occasion such as naming ceremony, housewarming ceremony, burial ceremony and other ceremonies is out rightly rejected. The elders do not tolerate unworthy PY, which joyfully graces almost all occasions in Ondo town. The stews accompanying the PY are either vegetable or okro wellloaded with bush meat or cow meat or fishes. Combination of meat and fishes are permitted with well-mixed Likotokiti for vegetable. Seldom will vegetable be prepared in Ondo town without Likotokiti (Ondo dialect for small-small mould of well-grinded mellon, spread in the vegetable).

During BBC, the female children of the deceased who have married have certain things their husbands should do and bring; a mention could be made of the followings:

(i) A big goat is required to be brought by each of the in-laws. If small goat is brought by anyone of them, Baba Musoku will reject it and demand that a bigger one be brought. There is time limit to do this, which may be before or on the 3rd or 7th or 8th day.

(ii) Thirty pieces of worthy mould of PYs are assigned to the in-laws to be brought on the 3rd or 7th or 8th or Jijo day.

There is no physical harm(s) done to anyone who fails to fulfill his obligations (i)-(ii), but his place of pride in his inlaw's house is forever dented. Thus, there is usually a healthy competition amongst the in-laws to bring something that is commendable. It is not only the direct deceased children inlaws who are requested to bring items (i)-(ii) above, other closer family children in-laws are assigned to bring either (i) and/or (ii) item(s). The purpose is for the family to have items to use throughout the period of the burial. The family enlarges their coast by asking each of the children to submit a worthy goat to the family toward the burial of their father/mother. With pool of goats and PYs, the family feed fine and not in lack of things to use at a funeral.

\subsection{Washing of Corpse}

There are professional corpse washers; old and young men doing this lucrative business for living now. Before now, there were not corpse washers; each family washed her corpse. By then, the corpse were seated and washed with warm water and local soap. If a woman, the plaited hair, if any before death, will be un-plaited. No explanation could be gotten for this. Two other things should be noted here: Water must not be poured on the head of the deceased, whether male or female. (b) The local sponge with the left-over water used to bathe the corpse must be kept. Any debtor who denied owing the deceased will be made to bathe with the sponge and water used for the corpse. Within few days, if the assumed debtor truly owed the deceased, he/she will also die for telling lie, else live. How hygienic is this procedure to claim debt(s)? Are there no other "local things" done along with this? Onehundred percent of the respondents consented this was the practice in the olden days, which has fallen into disuse.

It is forbidden to take the picture of the corpse while washing and shrouding it. This is to honour and give it maximum dignity. What is said to be washing today, to be frank, is cleaning the corpse with hand tower soaked in soap water. Materials required for cleaning corpse, apart from hand tower and soap (any type preferred by the children), are hand cloves which the washers wear and clean water(not necessarily warm water).

Has any crime been committed for not washing corpse before shrouded with grave clothes and buried? None! But love for the deceased prompted the children and the family to wash the corpse. Also, this is a long practice that has now been the norm in almost all societies in the world. A corpse buried without being washed and/or robbed, if while on earth did God's will through obedient faith in Christ, will be saved. All evildoers, though thoroughly washed with the best and expensive soap in the world, will find their portion in everlasting destruction awaiting all ungodly people (2 Thessalonians 1:6-9). Spiritually speaking, corpse washing has no significant value, since what determines each disembodied person's reward is obedient faith to Christ throughout life time (Matthew 24:13; Revelation 2:10). If you wash your corpse or not, you do not add an iota of value or blessing to the eternal reward the disembodied will receive from God.

\subsection{Burial Cloth in Ondo}

Generally, Ondo people fancy Aso Oke (local clothes) like Samiyan (most common local clothes). Most Ondos are seen dressed in well-sewed Aso Oke for important functions. A cross-section of folks at a burial in Ondo town is shown in figure 3. The first person in glasses was dressed in full attire of Aso Oke. Full attire here means Buba (underneath cloth, which is smaller than Agbada; and Agbada (flowing cloth; it is Aso Oke here, otherwise called 1500) with cap to match. Cap is generally removed (some may not do so) when service is on, as was the case here.

One can easily and quickly identify Ondos by their neat and elegant dressing, which should deserve discussion at another time. The common burial clothes are Aso Oke plus lace. Samiyan is demanded traditionally from each of the children of the deceased by the family; and some people bring it as Eni (Support/honour/ donation). 


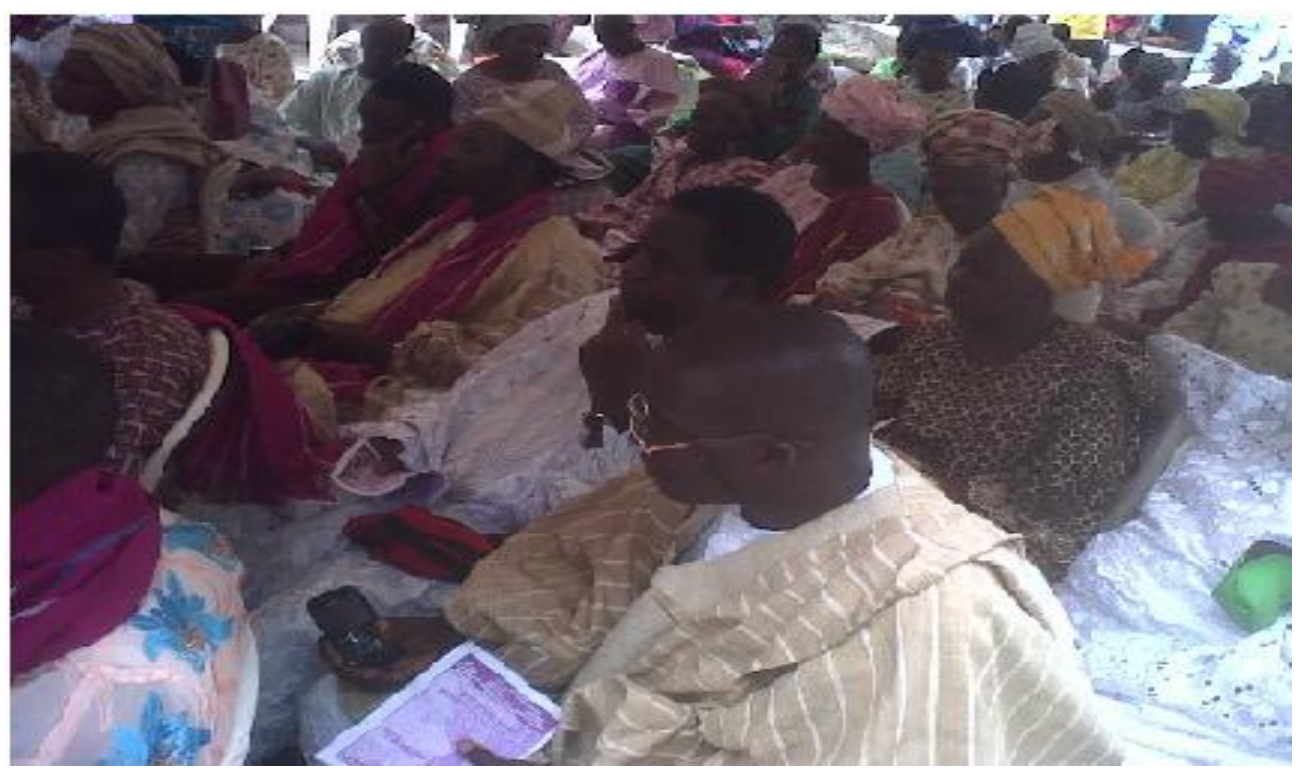

\section{Figure 3: Cross-section of people at a burial}

The corpse was shrouded with different pieces of the Samiyan clothes. But nowadays, it is not possible to say this is the exact uniform practice. About $75 \%$ of the interviewees agreed that things had changed; civilization had crept in to alter grave clothes in the town. The rest $25 \%$ of the respondents insisted that a true Ondo person makes use of Samiyan for burial. Unlike the olden days when boxers, vest and gloves were not utilized to shroud corpse, today corpses are decked with them as though going for sport. Thereafter, the corpse is robed in sewed white lace before being put in the coffin. One of the caps of the deceased is split one side and put on the head of the male deceased. Some of the Samiyan clothes are put by the sides of the corpse and at the feet for mere decoration. The point raised here about grave clothes is one of the practices; there are various other clothes that are used. The use of grave clothes are not new; they have been in use before and during Christ advent to the earth (John 11:44). Now, throughout the world most folks are still using burial clothes. It has been noted that burial clothes are of this world and have no spiritual significance in determining eternal destiny of any deceased [8].

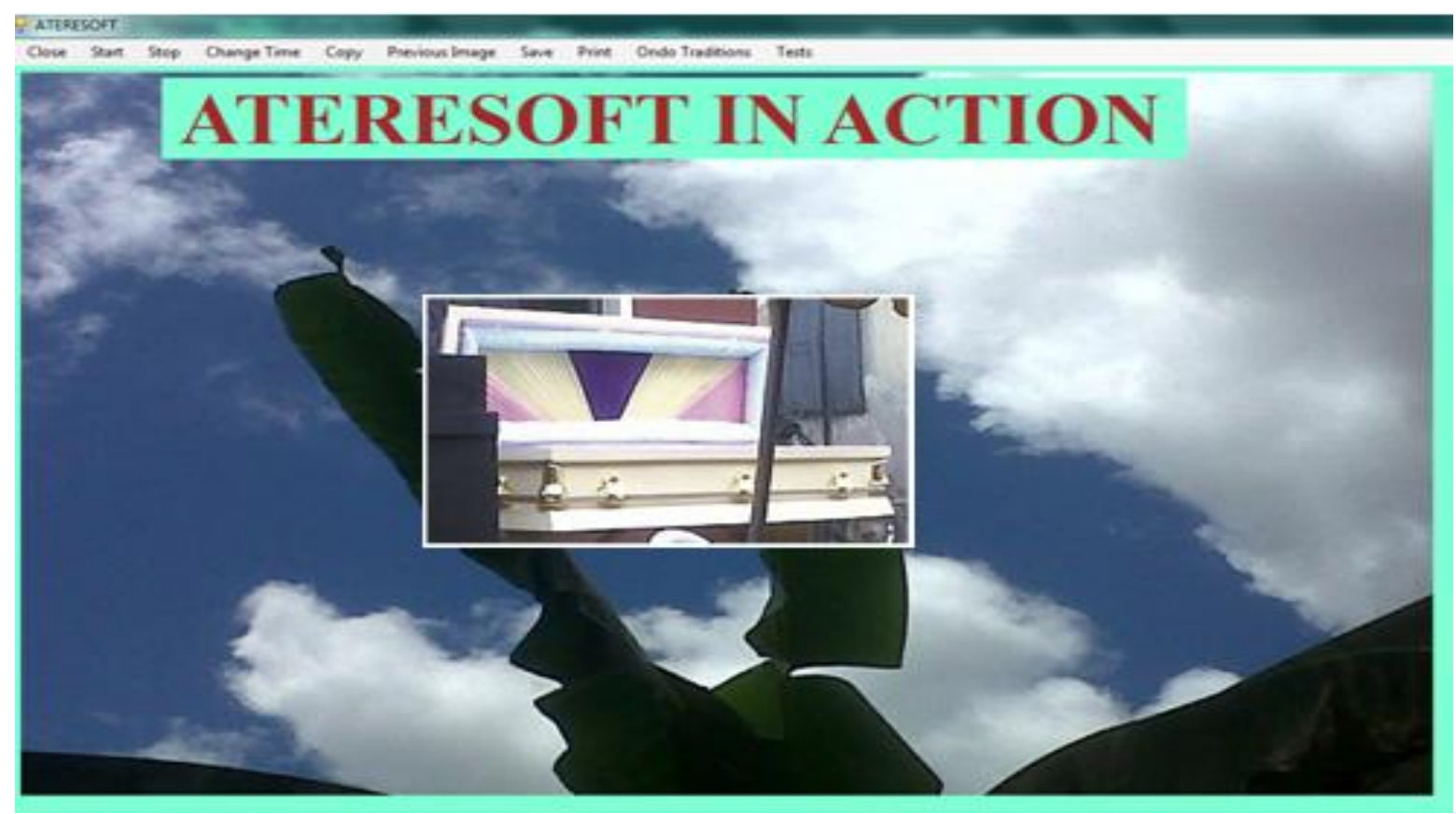

Figure 4: Client Application User Interface for Testing Components and Server

\section{CUSTOMIZED PICTURE BOX CONTROL}

Picture box control has been customized to be a silent, indefatigable and capable teacher to display images for default 3 seconds (3000 millisecond) and for any set time by user through dvSetInterval method. A client application was developed for exposing the functionalities of the customized picture box control. When Change Time main menu is pulled down, 1 second to 5 seconds submenus are displayed plus Other Times. By clicking any of these submenus, the timer interval is changed to reflect user's new desire immediately. 
However, when the last submenu of Other Times is clicked, user is prompted to key-in the required time, which is checked for validity; and if found worthy, it is converted to integer and passed to the dvSetInterval property to set new interval for the timer. This way, very slow viewers are not neglected, as well as fast beholders. Methods are called under the Start and Stop menus to commence and end image display respectively. Since the expected pictures to display most times will not be of the same size, the picture box control back colour can be altered through dvChgPicBxBackColour property, so that its back colour matches the client Application back colour, thereby preventing viewers from not seeing different background colours. A similar property for identical reason for the UserControl (UC) exists. For both, as soon as the change is effected, Invalidate method is called to update the concerned object. The default colour of BlanchedAlmond, the choice of the author, is set for both. Be reminded that UC is the platform for extrinsic control development [1-5].

During loading, dvPosnPicBxs function is summoned to position three pictures boxes at the same location for the same size mode of CenterImage. The Dock property of the picture boxes is set to fill and is also identical, but the images are not the same. The first box initially has no image; the other two boxes have permanent image loaded at design time that will be displayed in case of inability to display image dynamically and their visible property is permanently set to false. If any item under Ondo Traditions main menu of figure 4 could not be shown, the second picture box image is displayed by setting its image property to the first picture box image property.

There are three significant utilities expected on any displayed picture: copy, save and print, which could respectively be achieved through dvCopyPic, dvSavePic and dvPrintPic methods. If exception is thrown in case of unsuccessful loading or these useful operations could not be completed, image in picture box 3 will be displayed. Also, in all the operations, the timer is stopped and when completed or error occurred, it started again. This way, the present image in the picture box control is worked on. Previous Image menu displays previous image by calling dvPreviousPic method. In the screenshot of figure 4 , the second permanent picture box image is loaded into the first picture box to display only when loading UC.

\section{FILE CLASS LIBRARY}

A class library was developed to manipulate data files. There are useful functionalities in this server. The dvGetAllFilesMultiples is a powerful method that can load multiple filenames from a supply folder, which is the first argument. The second argument, a reference generic list collection of string, returns all the file names in the folder and its sub-folders. This method can be utilized in any project where file names are required for use.

A reference was made to the file class; and it was instantiated at server level. By calling this method of the file class at UC load event, all the file names in a folder, dvPicts and its subfolders are loaded for use. Up to one thousand images could be accepted for display, and any image that could not be loaded is discarded and the third picture box image will be loaded and shown in the first box where all the image is displayed one after the other.

Macintosh, use the font named Times. Right margins should be justified, not ragged.

Thus, the first box serves as image container for each displayed image; no permanent image is in it. For more discussion on picture box and its functionality, see [1- 4]. To prevent the UC from being resized at client side, its size is set at paint event of the UC.

Other methods in the file class are shown in Table 1, alongside the function(s) performed.

Table 1: Methods In The File Server

\begin{tabular}{|l|l|l|}
\hline S/N & Name & Function(s) \\
\hline 1 & dvChgFileExtnRemoveOriginal & Changes File Extension by replacing it with new one supply. \\
\hline 2 & dvCreateChgFileExtnRetainOrg & $\begin{array}{l}\text { Create a new File. Use the name of the supply file with the supply new Extension. } \\
\text { Don't alter the original file. }\end{array}$ \\
\hline 3 & dvChkFileOpenParas & Check File Missing Name. Check File Length. Check File Existence. \\
\hline 4 & dvChkFileSaveComparefExtn & $\begin{array}{l}\text { Calls dvChkFileOpenParas method. Compare the file extension supply with the } \\
\text { extension extracted from the file name supply. If not the same extension, report back. }\end{array}$ \\
\hline 5 & dvChkLetterDigit & $\begin{array}{l}\text { Check that the string sent in has only Letters and Digits and that it does not exceed the } \\
\text { specify length. }\end{array}$ \\
\hline 6 & dvChkMissingNam & $\begin{array}{l}\text { Check Missing File Name and Report back. This method is frequently called. For } \\
\text { instance, methods 3 and 5 use it. }\end{array}$ \\
\hline 7 & dvCreateFile & $\begin{array}{l}\text { Check valid name to be supplied. Create the supply file name after checking. Return } \\
\text { the File Stream for further use. }\end{array}$ \\
\hline 8 & dvDeleteFile & $\begin{array}{l}\text { Delete the supply file after asking user for confirmation. Check if file is opened. If it is, } \\
\text { close it and delete it. }\end{array}$ \\
\hline 9 & dvFileExist & Check if supply file exists. Frequently summoned by other methods (eg S/N 1,3) \\
\hline 10 & dvOpenSaveTxt & Save the supply text to a file name supply internally by user. \\
\hline
\end{tabular}




\section{CLIENT DEVELOPMENT}

A Windows Application, AtereSoft, was developed with Microsoft Visual Studio, 2013. A copy of the picture box extrinsic control developed was added to the package through Toolbox General Category. By clicking Start main menu, pictures in dvPicts folder are displayed sequentially. This is carried out directly in the picture box customized control. What is done in this Application is to position the customized control when form loads. When Ondo Traditions main menu is clicked, four submenus of Ewe(leaf), Unakere. Akoun and Unakere_Akoun are shown. On clicking the first submenu, the local Ewe (leaf) picture will be shown with brief comments. The picture of Unakere and Akoun are displayed separately when the second and third submenus are clicked and with the fourth submenu both will be shown together.

\section{BRIEF COMMENTS}

The appointment of Baba Musoku, the male head at a funeral, is generally done in all funerals in Ondo to checkmate excesses of children, relatives and other folks who would like to cause trouble(s) during the entire funeral period. A younger person, not older person, to the deceased whose tenure ended as soon as the funeral is over, is appointed. He may still, however, be summoned to assist in sharing the deceased properties to the bellicose children at anytime. In this everexpanding town, older brothers and relatives to the deceased do not attend their younger brothers' funeral. They stay indoor to mourn. However, outsiders older than the deceased could be seen at a younger person's funeral to wine and dine. The general prayer is that the elder should put off the tent before the younger. As usual, a good head-ship implies peace, orderliness and success, which also applies to funeral and Baba Musoku. Ondo people are orderly and peace-seeking people who always are pacesetters in all worthy life endeavours.

Since nobody could give sound reason why the grave of a person who gave birth could not be completed in a day, we assume it is a mere taboo that has no harmful effects on the deceased living people. Yet there is still the need to get more elders to speak on the effect(s) of digging and not digging a grave yard of a deceased who gave birth in a single day. For now, the implication is that the grave yard of a barren deceased has to be dug in a single day. Is this not to distinguish a barren deceased from non-barren deceased? Why should this distinction be permitted?

All the items shown under Ondo Traditions main menu are animated for three seconds, but the timer interval could be changed through Change Time menu to speed-up or delay viewing. Also, any of the item could be persisted in any media user wants and hold a hardcopy by printing them. Those viewing the clear pictures indirectly are made to see and learn about Ondo cultures. This way, we put our heritage inside the computer and preserve what should be preserved for generations yet un-born.

The corpse washers are expected to wear overall and mouth cover, which recently they did not do as observed. Proper education for these workers would assist them not to easily contact disease. Frequent check-up at well-equipped hospitals will equally be of benefit to them. At present, they do not have Association under which they could have gotten some benefits and proper direction. This should be put in place.

It was observed that leaf wrappers were used for wrapping PYs as could be seen in figure 1 instead of nylon. The use of leaves as PYs wrappers was a traditional way of dressing PYs for occasions in Ondo. Now, however, folks use nylon as wrapper and the elders accept it. Thus, the use of leave is fast fading out due to the convenience offers by nylon, as well as ready availability of nylon.

The goats of the Aremos are mandatory for BBC: that of the Aremo Okunrin will be slaughtered on the burial day and that of the Aremo Obinrin on the 3rd day. The goats of the other children, if not available due to lack, are to be brought later and killed. This may be during the remembrance of the deceased when the children now have money. Though not compulsory that other children should bring theirs, it is desired, so that enough materials will be available for use during the BBC. Any children of the deceased who could not bring a goat to support $\mathrm{BBC}$ is not regarded to have buried the deceased. In view of this, children often borrow to buy and bring the goat to the family during BBC. It is in extreme situation of penury that goat is deferred till remembrance period of the deceased. Availability of goats and drinks determine how the family feasts at a funeral and how they are happy to be in such gathering.

When wives knee down before a celebrant, which may be for a long or short period, shaking their bodies, they traditionally honour the celebrant and want the celebrant to reciprocate this by given them worthy money. Therefore, kneeing of wives at a function in Ondo is not to punish or disgrace the wives. Ondo wives, regardless of age, are clever at doing this; thus celebrants should have enough change on him/her to spend, so as not to be disgraced when he/she could not give as demanded by the culture of the land.

Have some or all the present electronic gadgets been in existence in the olden days, most of the questions unanswered in this work could have be gotten from the archives. This indicates the urgent needs to glean and document our cultural beliefs.

The file server was comprehensively tested via the Tests main menu of figure 4; and the functionalities in it function to specifications. It will hasten applications' development. Further use, besides the one used with the customized picture box control, is expected of all the functionalities to reveal their capability. The length of the codes in the customized control properties, functions and methods is very short, yet the codes work effectively to achieve desired result(s). Therefore, it is not code length that determines its capacity, usefulness and significant; rather the purpose for which the control was developed, and the effective way it is coded to perform the task at hand are the determinant parameters. Nice that users could upload their pictures through dvPicts folder, but it will be far better if each user has more power to supply any folder. Pictures in a folder could be corrupted or accidentally deleted, thus a better method to hold the pictures is expected.

\section{CONCLUSION}

Several step-by-step traditional funeral rites in Ondo town are discussed. The Ondos esteemed PYs for occasions. Unworthy PYs are the ones with ema, which Baba Musoku rejects. Corpses were carefully washed then, so that water would not touch their head. Now, they are cleansed with soap-soaked hand towel, no fear of water reaching the head. Corpses are shrouded with grave clothes, especially Aso Oke. Also, grave digging is the pride task of the in-laws; without them, the family and/or the children take over.

The accuracy of the file server developed with Microsoft Visual Studio, 2013 and used along with the customized picture box control, was confirmed through a client 
application developed. This server works accurately and promises to aid future projects to be completed to time. The customized picture box control for image display is flexible to use and handy to speed-up other Developers' work. We succeeded in putting Ondo traditions inside computer as some selected items with comments could be displayed and animated to bring about teaching and learning.

Although this is the first major attempt to reveal the rich cultures of Ondo people during BBC, there are still much to unearthing and disclose. The traditional drums and drummers have not been addressed. Several questions are asked about some things and materials concerning funeral in Ondo town which have not been answered, begging for sound answers. Although displayed image could be saved, copied to clipboard and printed, there is no provision to flip, rotate and crop the image, which limits the capabilities of the customized picture box control. Adding more functionalities to the file server will further enhance its usefulness. The pictures for Unakere and Akoun are insufficient; more so, more submenus are to be included to depict some unique features of Ondo funeral rites.

List of Abbreviations

\begin{tabular}{|l|l|}
\hline Abbreviation & Meaning \\
\hline Abebe & Hand fan \\
\hline Agbada & Flowing cloth, otherwise called 1500 \\
\hline Akoun & Burial and Burial Ceremony \\
\hline BBC & Father of burial \\
\hline Baba Musoku & Cloth wears underneath Agbada; smaller than Agbada \\
\hline Buba & Small-small-yam-pebble inside pounded yam \\
\hline Ema & Leaf \\
\hline Ewe & Mother of burial \\
\hline Iya Musoku & Small-small mould of well-grinded mellon, spread in vegetable soup \\
\hline Likotokiti & Ondo people \\
\hline OP & $\begin{array}{l}\text { Cookers (Food contractor, mostly women contracted out food to, to prepare for occasions } \\
\text { such as naming, house-warming and funeral ceremonies) }\end{array}$ \\
\hline Olowosibi & Pounded yam \\
\hline PY & Unakere \\
\hline
\end{tabular}

\section{ACKNOWLEDGEMENTS}

i) All Scripture taken from the New King James Version. Copyright (C) 1982 by Thomas Nelson, Inc. Used by Permission. All rights reserved.

ii) Immense gratitude to folks and relatives who permitted chats into uncommon areas of death and BBC often neglected and unaddressed for discussion.

\section{REFERENCES}

[1] Evangelos Petroutsos 2010. Mastering Microsoft Visual Basic 2010. Wiley Publishing Inc.

[2] Craig Utley 2001. A Programmer's Guide to Visual Basic. NET. Sams Publishing.

[3] Dave Grundgeiger 2002. Programming Visual Basic .NET. O' Reilly and Associate. Inc.
[4] Thearon and Bryan 2010. Beginning Microsoft Visual Basic 2010. Wiley Publishing Inc.

[5] Tim Patrick 2008. Programming Visual Basic 2008. O' Reilly and Associate, Inc.

[6] Adenugba, D.A. 2007. Meeting Expectations With Dynamic Link Libraries: Development And Applications. IJCA. 36(9); 47-54.

[7] Adenugba, D.A. 2007. An Atmospheric Server for Some Atmospheric Parameters: Development and Applications. J. Res. Sci. Mgt. 5(1): 91-104.

[8] Adenugba, D. A. 2014. Last Farewell. FemoBless Publications. 